\title{
Cold Plasma for Food Processing as a Novel Technology- Mini Review
}

\author{
Serajoddin Razavizadeh, Saeedeh Faghih Haghani and Hamid Ghomi* \\ Laser and Plasma Research Institute, Shahid Beheshti University, Iran \\ *Corresponding author: Hamid Ghomi, Laser and Plasma Research Institute, Shahid Beheshti University, Tehran, Iran
}

Keywords: Cold Plasma; Non-Thermal Plasma; Surface Modification; Plasma Jet; Dielectric Barrier Discharge; Decontamination; Sterilization

\section{Introduction}

In the past decade, non-thermal plasmas such as atmospheric plasma jets, dielectric barrier discharges, corona discharges and even gliding arc discharges are widely used for food processing $[1,2]$. The cold plasmas are effective for food decontamination [3], food packaging modifications [4], enzyme inactivation [5], toxin removal [6] and wastewater treatment [7]. Also, the effect of cold plasma on endogenous enzymes and seed germination is widely studied [2]. The advantages of cold plasmas over the traditional methods lies with non-thermal, economical, versatile and environmentally friendly nature. The cold plasmas contain many chemical species like ions and metastable molecules that can interact with bio-surfaces and also the ultra-violet radiations can take part in decontamination processes $[5,8]$. In this brief review, we will introduce the most used plasma sources in food industries and their application.

\section{Atmospheric Plasma Jets}

Atmospheric pressure plasma jets (APPJs) produce a non-thermal plasma flame that are typically generated in the radiofrequency range. Plasma jets often consist of two electrodes: high voltage electrode and the ground electrode, but there are some plasma jets that only have one powered electrode. The major advantages of plasma jets are their small dimensions, their targeted applicability, and their ability to also penetrate into narrow gaps [9]. The plasma jets are widely used in surface decontamination and increase of wettability of the vegetable's seeds [10]. Most of the plasma jets uses helium and argon as the working gas and sometimes mixed with nitrogen and oxygen to create more ionized species.

\section{Dielectric Barrier Discharges}

In dielectric barrier discharges (DBDs), a non-thermal plasma is commonly generated between two electrodes that are separated by a dielectric [8]. Usually, A.C. voltage with amplitude of $1-100 \mathrm{kV}$ and a frequency of a few $\mathrm{Hz}$ to $\mathrm{MHz}$ is applied to the discharge. The big advantages of DBDs are the great variety of gases that can be used, the possibility to ignite homogenous discharges over several meters as well as the good adaptability due to different electrode geometries. DBDs can use to increase wettability and germination rate of seeds such as cotton, soybeans and wheat [11,12]. Figure 1 shows the treatment of pistachio and almond by DBD plasma. 


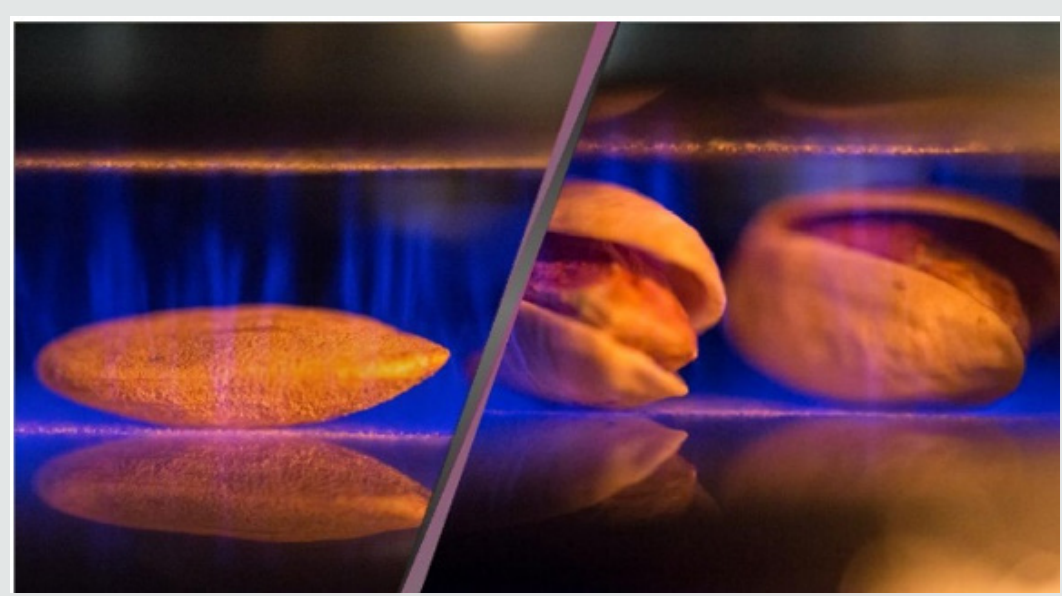

Figure 1: The treatment of pistachio and almond by DBD plasma.

\section{Corona Discharges}

Corona discharges appear near sharp electrode geometries where the electric field is sufficiently large to accelerate electrons up to the ionization energy level of surrounding gas atoms or molecules [13]. Typical geometries are point-to-plate geometries and cylindrical geometries. Corona discharge applications are limited to non-uniform treatments of comparably small areas. Choi et al. [14] used the corona discharge for microbial decontamination of dried Alaska pollock shreds.

\section{References}

1. Tolouie H, Mohammadifar MA, Ghomi H, Hashemi M (2018) Cold atmospheric plasma manipulation of proteins in food systems. Critical reviews in food science and nutrition 58(15): 2583-2597.

2. Thirumdas R, Sarangapani C, Annapure US (2015) Cold plasma: a novel non-thermal technology for food processing. Food biophysics 10(1): $1-11$.

3. Dorraki N, Mahdavi V, Ghomi H, Ghasempour A (2016) Elimination of diazinon insecticide from cucumber surface by atmospheric pressure air-dielectric barrier discharge plasma. Biointerphases 11(4): 041007.

4. Pankaj SK, BuenoFerrer C, Misra NN, Milosavljević V, Odonnell CP, et al. (2014) Applications of cold plasma technology in food packaging. Trends in Food Science \& Technology 35(1): 5-17.

5. Misra NN, Pankaj SK, Segat A, Ishikawa K (2016) Cold plasma interactions with enzymes in foods and model systems. Trends in Food Science \& Technology 55: 39-47.
6. Misra NN (2015) The contribution of non-thermal and advanced oxidation technologies towards dissipation of pesticide residues. Trends in Food Science \& Technology 45(2): 229-244.

7. Sarangapani C, Misra NN, Milosavljevic V, Bourke P, ORegan F (2016) Pesticide degradation in water using atmospheric air cold plasma. Journal of Water Process Engineering 9: 225-232.

8. Surowsky B, Bußler S, Schlüter OK (2016) Cold plasma interactions with food constituents in liquid and solid food matrices. In Cold plasma in food and agriculture pp. 179-203.

9. Weltmann KD, Brandenburg R, Von Woedtke T, Ehlbeck J, Foest R, et al. (2008) Antimicrobial treatment of heat sensitive products by miniaturized atmospheric pressure plasma jets (APPJs). J Phys D Appl Phys 41(19): 194008

10. Hertwig C, Meneses N, Mathys A (2018) Cold atmospheric pressure plasma and low energy electron beam as alternative nonthermal decontamination technologies for dry food surfaces: a review. Trends in Food Science \& Technology 77: 131-142.

11. De Groot GJ, Hundt A, Murphy AB, Bange MP, Mai Prochnow A (2018) Cold plasma treatment for cotton seed germination improvement. Scientific reports 8(1): 14372.

12. Tolouie H, Mohammadifar MA, Ghomi H, Yaghoubi AS, Hashemi M (2018) The impact of atmospheric cold plasma treatment on inactivation of lipase and lipoxygenase of wheat germs. Innovative food science \& emerging technologies 47: 346-352.

13. Raizer YP, Allen JE (1991) Gas discharge physics. Springer, Berlin 1.

14. Choi S, Puligundla P, Mok C (2016) Microbial decontamination of dried Alaska pollock shreds using corona discharge plasma jet: effects on physicochemical and sensory characteristics. Journal of food science 81(4): 52-957.

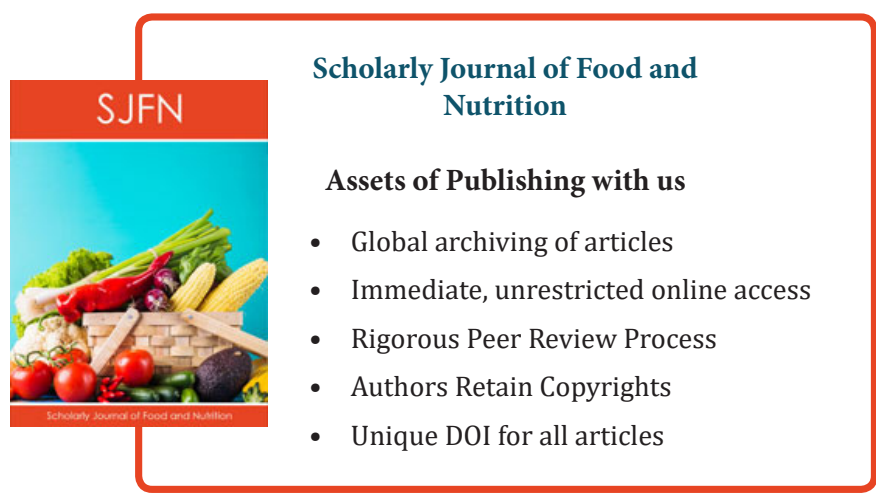

